\title{
Un estudio general de las artes y la política de Nepal durante el siglo XX: Procesos de transición y diálogo multicultural
}

\author{
A general study of the arts and politics of Nepal during the \\ XX century: Processes of transition and multicultural dialogue
}

\author{
Andrea de la RUBIA GÓMEZ-MORÁN \\ Universidad Complutense de Madrid
}

Recibido: 11-V-2015

Aceptado: 28-III-2016

Resumen: Este trabajo consiste en un estudio generalizado del desarrollo del arte moderno nepalí en torno a los años 50, cuando la cultura del país comenzó un proceso de transformación como consecuencia de su reapertura al mundo exterior y consiguiente relación con occidente. Durante esta transición, tanto el cambio político producido por las nuevas ideas democráticas como los nuevos medios de comunicación, contribuyeron a la creación de un nuevo Nepal dividido entre lo moderno y lo tradicional. El objetivo de este estudio es el de subrayar que el arte moderno nepalí se desarrolló a partir de su propia localidad pero también debido a la influencia de los procesos capitalistas característicos de la globalización cultural.

Palabras clave: Nepal, Democracia, Arte moderno, Hibridación, Revolución, Transformación.

AвstRACT: This paper consists of a general study about the development of modern Nepali art around the fifties, when the culture of the country began a process of transformation as a consequence of its reopening to the outside world and relationship with the West. During such transition, both the political changes brought about by the new democratic ideas and the new media communication, contributed to the creation of a new Nepal divided between the modern and the traditional. The aim of this study is to highlight that Nepalese modern art has been developed from its own locality, but also due to the influence of the cultural globalization's capitalist processes.

Keywords: Nepal, Democracy, Modern Art, Hybridization, Revolution, Transformation.

Entre los años abarcados entre el final de la monarquía Rana en 1950 y la restauración de la democracia en 1990, Nepal experimentó muchos cambios: la población dobló su número, se construyeron carrete- ras, el sistema educativo mejoró y el turismo se vio incrementado. Actualmente los procesos capitalistas están cada vez más integrados en lugares geográficamente dispersos, provocando la globalización, y 
es por ello que podemos afirmar que Nepal se ha convertido a día de hoy en un miembro activo de la comunidad internacional. Los estudios etnográficos remarcan cómo las relaciones político-económicas se viven en el contexto local, centrando dicho discurso en el imperialismo cultural. Dichos estudios remarcan que mucha de la ansiedad relacionada con la idea de globalización tiene que ver con la ambigüedad cultural, en los efectos producidos y atribuidos a la misma. Sin embargo, estas teorías olvidan el hecho de que la cultura no es un objeto pre-constituido y que las comunidades van cambiando a medida que reconvierten los procesos globales en procesos locales $^{1}$. La visión popular de Nepal como un país remoto, donde las altas montañas protegen la cultura ancestral de toda contaminación del mundo moderno comenzó a generarse cuando los hippies adoptaron Katmandú como destino popular. Sin embargo, la realidad que hoy en día recibe al visitante es bastante más compleja. La palabra "modernismo" es normalmente atribuida al contexto occidental, ignorando la multiplicidad de significados que esta palabra puede esconder según el lugar donde se aplique. El mundo moderno es moderno para todos, por lo que este estudio se plantea desde la aceptación de la existencia de la modernidad en Nepal como parte de su cultura actual ${ }^{2}$. El objetivo de este artículo es el de realizar un trabajo de campo general que nos permita conocer la evolución del arte y la cultura nepalí a partir de los años 50, comprendiendo su desarrollo dentro de su propio contexto multicultural, estableciendo así una base general para posibles futuras investigaciones que profundicen en cada uno de los temas abiertos.

${ }^{1}$ K. NEILSON RANKIN, The cultural Politics of Markets. Economic liberalization and social change in Nepal, London, 2004, p. 46.

2 A. SUBHEDI, "Modernity and Nepali Art", Chautara Gallery (en línea), 2013, consultado el 30 de Enero del 2015. URL: http://www.chautara.nl/art-in-nepal/arthistory0/influence $0 . h t m l$

\section{EL REALISMO OCCIDENTAL}

Nepal es un país dividido geográficamente en tres zonas diferenciadas: las montañas al borde del Tíbet, la zona media del Valle de Katmandú y la selva del Terai, frontera con la India. El Valle de Katmandú siempre ha mantenido relaciones económicas con sus países vecinos, siendo por ello un importante centro de nexos culturales. En Nepal habitan actualmente alrededor de 62 grupos étnicos diferentes como resultado de la relación y mezcla entre los Tibeto-Burmanos emigrados del Norte y los Indo-Arios del Sur, cada uno con su propia lengua y cultura. Desde que tuvo lugar el proceso de unificación del país, iniciado por el Rey Pritvi Narayan Shah en el siglo XIX, el nepalí se convirtió en la lengua oficial y la comunidad se organizó bajo las reglas de la tradición hindú y sistema social de castas. Dicho sistema dividió la sociedad en cuatro grupos: brähmana (sacerdotes y estudiantes), chetris (jefes y guerreros), vaishya (mercaderes y comerciantes), śūdra (granjeros, artesanos y trabajadores) y dalits (el grupo marginal). Tras la guerra Anglo-Nepalí de 1814-1816 entre la monarquía Shah y la British Indian Company por el territorio del Terai, los británicos se establecieron como el poder más fuerte del subcontinente asiático tomando gran parte del territorio nepalí. Pero una vez el General Jung Bahadur Rana se hizo con el poder en 1846, los británicos adquirieron una postura más conciliatoria con respecto a Nepal. Los Rana apoyaron al British Raj ofreciéndole regimientos de soldados Gorkha para paliar los levantamientos indios de 1857, por lo que éstos devolvieron a Nepal algunas de las zonas del Terai ganadas tras la guerra. La cercana cooperación entre el régimen Rana y la colonia británica aseguró el hermetismo de Nepal con respecto a su relación con otros países extranjeros. Sin embargo, debido a los nuevos medios de comunicación así como a la creciente emigración la influencia fue inevitable. Esto provocó una nueva moda de distinción social a través del consumo de bienes importados, originando la nueva ca- 
tegoría de clase media en la jerarquía social de Katmandú ${ }^{3}$.

Por tanto, a pesar de que históricamente la religión y la espiritualidad han dominado la sociedad y cultura de Nepal, poco a poco las formas de arte occidentales comenzaron a tener presencia en el país. Los primeros intentos de utilizar los nuevos conceptos de perspectiva, sombra y luz ocurrieron a principios del siglo XIX con el artista Raj Man Singh Chitrakar, el cual, bajo la tutela del antropólogo británico Brian Houghton Hodgson ${ }^{4}$, experimentaba con las formas tridimensionales de la naturaleza mediante dibujos a lápiz y acuarela. Asimismo, en 1850 el General Jung Bahadur Rana viajó a Londres acompañado por un grupo de artistas Citrakar ${ }^{5}$. Impresionado por el poder que reflejaba el arte europeo, el General mandó construir a su vuelta grandes palacios a semejanza del estilo neoclásico occidental. Al mismo tiempo, la necesidad de decorar estos palacios llevó a los Rana a fomentar el estilo realista occidental en la pintura nepalí, encargando a los artistas grandes retratos al óleo similares a los que se hacían en Calcuta para el British Raj ${ }^{6}$. Bajo este cometido, los Rana enviaron artistas como Chandra Man Singh Maskey ${ }^{7}$ o Tej Bahadur Chi-

${ }^{3}$ M. LIETCHY, Suitably modern. Making middle-class culture in a new consumer society, Princeton, 2003.

4 Brian Houghton Hodgson, británico en Katmandú, estudiaba literatura, zoología y religiones del Himalaya. Raj Man Singh Chitrakar trabajó para Mr. Hodgson como artista desde 1820 hasta 1850. En M. CHITRAKAR, "Raj Man Singh Chitrakar (1797-1865): The discovery of a pioneer artist", en Nepali Art, Kathmandu, 2012, pp. 2-15.

${ }^{5}$ Los artistas Citrakar pertenecen a la etnia Newar del Valle de Katmandú. Tradicionalmente son pintores Paubhā de templos, así como escultores de máscaras para bailes rituales. La traducción literaria del nombre Citrakar es "constructor de imágenes".

${ }^{6}$ Bhaju Man Chitrakar fue el primer pintor en adquirir el estilo realista en su obra. En S. UPRETY, "Cultural Aesthetics of the Contemporary", Bhodi. An Interdisciplinary Journal, vol. 4, n¹, 2010, pp.100-110.

7 Al volver a Nepal en 1928, Maskey organizó la primera exhibición de arte de la historia de Nepal. Comenzó a enemistarse con los Rana al fundar una escuela pública y en 1940 fue encarcelado durante cinco años

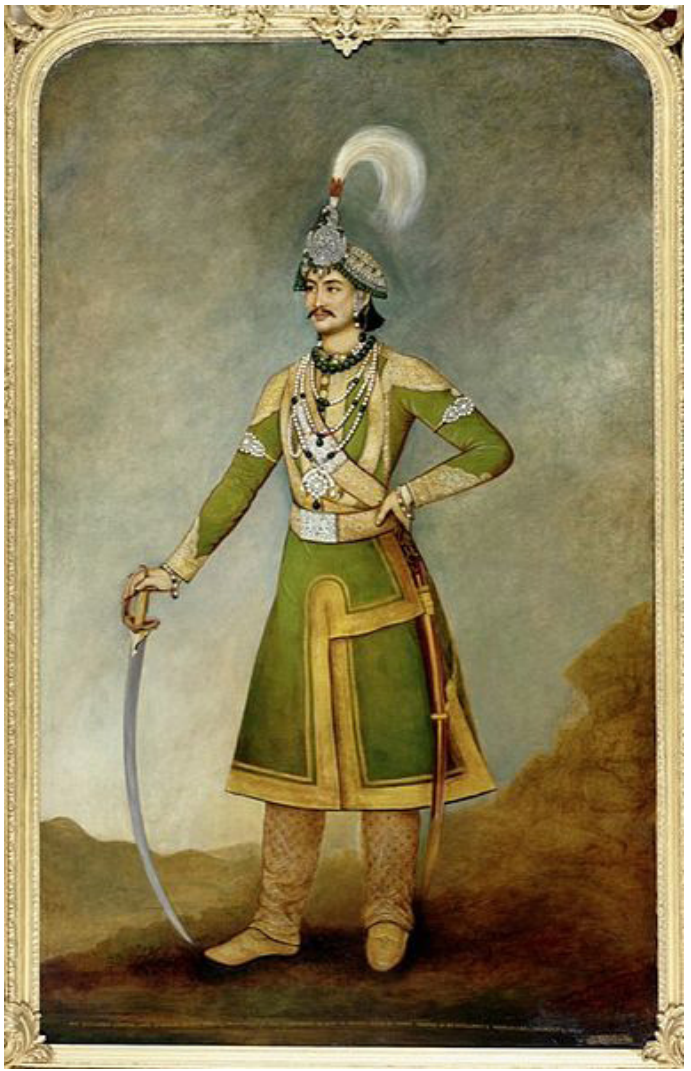

- Fig. 1. Bhaju Man Chitrakar. Jung Bahadur Rana (1817-77). 1849. Chawni Museum, Katmandú. Foto de la autora.

trakar a especializarse en el arte del retrato en la Government Art School de Calcuta en India. Asimismo, otro tipo de técnicas comenzaron a introducirse en el país, como por ejemplo la técnica de la fotografía realizada por Dirgha Man Chitrakar, el cual acompañó al Primer Ministro Chandra Shumsheree Rana en su viaje a Londres en 1908. La moda del realismo occidental permanecería presente en el arte nepalí como reflejo del poder de los Rana hasta la revolución en los años 50 (Fig. 1).

Durante la era Rana el sistema educativo nepalí brillaba por su ausencia, por lo que muchos intelectuales de clase media emigraron a la India para recibir una educación de calidad. Estos grupos exiliados desarrollaron una conciencia política motivada por los movimientos indios independentis-

como castigo al ser acusado de dibujar una caricatura en contra del régimen. En M. CHITRAKAR, Tej Bahadur Chitrakar. Icon of a transition, Kathmandu, 2004. 


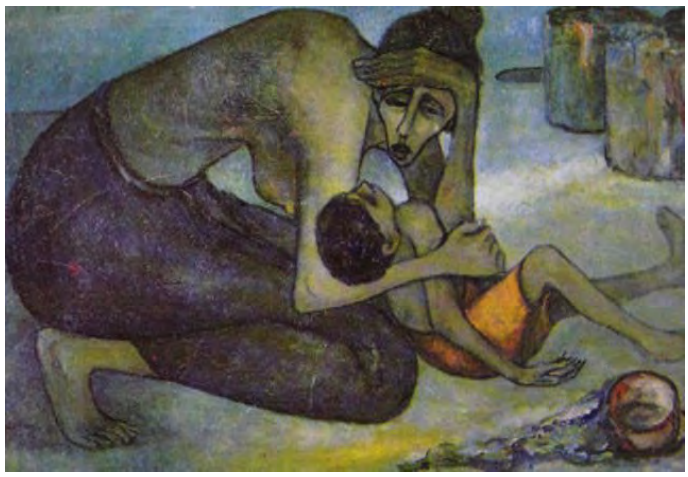

- Fig. 2. Lain Singh Bangdel. Famine in Bengal (Hambruna en Bengal). 1950. Colección de Dina Bangdel.

tas, y crearon nuevos partidos que tendrían mucha importancia en el futuro, como el pro-democrático Nepalí Congress Party. Sin embargo, el primer partido en contra el régimen fue el Praja Pharishad, el cual surgió en Katmandú en 1935. Sus miembros fueron ejecutados públicamente convirtiéndose en los primeros mártires por la causa e inspirando a los partidos políticos venideros ${ }^{8}$. Por su parte los estudiantes exiliados utilizaron la literatura como medio para resistir al poder Rana, formando la primera organización literaria en 1926. En 1939 Lain Singh Bangdel, escritor y pintor relevante en cuanto al posterior desarrollo del arte moderno nepalí, se dirigió a la Government Art School de Calcuta para estudiar arte, donde pronto se vio influenciado por el estilo de sus compañeros exiliados y novelistas europeos, comenzando a escribir historias realistas sobre las vidas de la gente común que le rodeaba9. Asimismo, en 1945 presenció la hambruna de Bengal en las calles, reflejando posteriormente esta la experiencia en su obra cuando

${ }^{8}$ S. R. DEVKOTA, Nepal in the XXI Century. Global Political Studies Series, New York, 2010.

${ }_{9}$ Como Outside the Country 1948, Maternal Home 1950 y The Cripples Friend 1951. Además Bangdel fundó en India una pequeña revista literaria llamada Prabhat en la que publicaba poesía, historias escritas por los maestros europeos, y artículos que hablaban sobre música y arte occidental. En D. BANGDEL y D. MEESSERSCHMIDT, Against the current. The life of Lain Singh Bangdel. Writer, painter and art historian of Nepal, Bangkok, 2004 ya residía en Londres unos años más tarde ${ }^{10}$ (Fig. 2).

Al mismo tiempo en Nepal las sociedades religiosas comunales organizaban encuentros clandestinos para concienciar a la gente sobre sus derechos y deberes y se comenzaban a establecer las primeras librerías. A pesar de que solo una pequeña parte de la población era capaz de leer o escribir, la poesía de los artistas exiliados floreció y se extendió porque podía ser leída en voz alta y transmitida boca a boca. Bhupi Sherchan ${ }^{11}$, poeta exiliado en Benarés, fue uno de los literatos más relevantes al adoptar la figura de los mártires como representaciones de la lucha por la libertad. Por mucha censura que impusieran, los Rana no pudieron aislar a Nepal de los influjos independentistas que venían de la India, cuya Guerra por la Independencia finalizó en 1947. No fue coincidencia que la monarquía Rana, que había crecido a la par que la consolidación de la colonia británica, cayese poco tiempo después.

\section{LA DEMOCRACIA PANCHAYAT}

A partir de 1950 Nepal se abrió por vez primera al extranjero, restableciéndose la monarquía con el Rey Tribhuvan Shah junto a un nuevo sistema de gobierno democrático. Tras su fallecimiento en 1955, Tribhuvan fue sucedido por su hijo Mahendra Shah, y en las elecciones para el Parlamento de 1959 resultó elegido el Nepalí Congress Party con B.P.Koirala como Primer Ministro. Pero el Rey Mahendra, considerando la democracia como una amenaza hacia su mandato, eliminó el Parlamento en 1960 y encerró a Koirala en prisión. Seguidamente, estableció un nuevo sistema denominado como el sis-

\footnotetext{
${ }^{10}$ Ibídem.

${ }^{11}$ Bhupi Sherchan (1937-1990) fue premiado con el Sajha Puraskar en 1970 por su colección de poemas Ghumne Mech Mathi Andho Manche (El hombre ciego en un asiento revoltoso). Fue el poeta con más éxito al popularizar el verso libre. También escribió odas a los mártires de Nepal como Sahid Ko Samjhana, Main Batti Ko Sikha, y Ghantaghar. En M. HUTT, The life of Bhumpi Sherchan. Poetry and politics in post-Rana Nepal, Oxford, 2010.
} 
tema Panchayat, a través del cual aseguraba la supremacía del monarca al mismo tiempo que cumplía con los mínimos requeridos en cuanto a las aspiraciones democráticas del pueblo. Este sistema buscaba crear una nueva población culturalmente homogénea, promoviendo el hinduismo y el nepalí como significantes de la identidad nacional bajo el eslogan "Una lengua, una forma de vestir, un país". La identidad nepalí era fomentada diariamente por medio de Radio Nepal, que emitía diariamente música ritual y sermones tradicionales $^{12}$. El Rey Mahendra gobernó hasta que en 1972 fue sustituido por su hijo Birendra Bikram Shah, el cual continuó con el régimen Panchayat previamente estableci$\mathrm{do}^{13}$.

A partir de 1951 la industria turística y las Organizaciones No Gubernamentales (ONG) se convirtieron en los focos más importantes para el desarrollo de la economía en $\mathrm{Nepal}^{14}$, por lo que la clase media consumista aumentó. Gracias a la ayuda internacional el sistema educativo nepalí comenzó a mejorar y se fundaron colegios y universidades, como la Tribhuvan University en $1956^{15}$. Asimismo, la publicidad surgida junto a los nuevos medios fomentó la sociedad consumista en Katmandú ${ }^{16}$. Según Arjun Appadurai, la publicidad crea en el sujeto un sentimiento de nostalgia ficticia y apunta a los medios de masas como uno de los factores fundamentales en la aceleración del cambio cultural por su habilidad en expandir la

${ }^{12} \mathrm{M}$. LIETCHY, Fashioning modernity in Kathmandu: Mass media, consumer culture and the middle class in Nepal, Philadelphia, 1994.

${ }^{13}$ M. HUTT, Op.cit.

${ }^{14}$ Antes de la llegada de las ONGS, muchas comunidades de Nepal ya contaban con la tradición del Guthi, cuyo propósito era la caridad y el bienestar de la comunidad.

${ }^{15}$ S. SHARMA, "Role of Foreign Aid in Transformation", en Nepal. Transition to Transformation, Kathmandu 2008.

${ }^{16}$ B. BAHADUR, S. BASNET y S. NAUPANE, Social development and INGOs activities in Nepal, Kathmandu, 1999. fuerza de la imaginación en la vida diaria ${ }^{17}$. En sus referencias constantes al consumismo moderno en forma de vídeo, música pop, cine, moda...los jóvenes nepalíes participan en una especie de globalización que construye su propio mundo basado en imágenes y deseos, atrapados entre el proceso modernista y sus raíces en la tradición. Mark Lietchy declara que, en realidad, la clase media consumista de Nepal está intervenida por el sistema local de castas y otras creencias religiosas apoyadas en discursos de honor y prestigio: ser "clase media" en Nepal conlleva participar en un dialogo social y cultural de lo que significa ser moderno. Ijar en nepalí significa prestigio, dignidad, respeto, honor...lupa a través de la cual se incluye la "clase media" en la sociedad tradicional nepalí, a través de la moderación del consumo dentro de límites comúnmente impuestos ${ }^{18}$. Asimismo, los nuevos medios en Nepal estaban supeditados a la censura impuesta por el sistema Panchayat. La libertad de prensa era controlada por el Acto de Ofensas Públicas y Castigo, por lo que muchos vieron la literatura como una buena alternativa para la libre expresión. La poesía nepalí se mantuvo independiente por medio de un código irónico y perspicaz, a través del cual publicaban sus sentimientos en contra del régimen ${ }^{19}$. Bhupi Sherchan volvió a Nepal en 1955 y formó un colectivo político llamado Rodi junto a los poetas Vashu Shashi, Kumar Nepal, Mohan Himanshu Thapa y Krishna Bhakta Shrestra. Este grupo organizaba encuentros literarios con un estilo de vida bohemio, desafiando el moderado comportamiento tradicional de cualquier nepalí. En 1957 estos poetas participaron en un movimiento civil que expresaba su desacuerdo ante el retraso que el Rey Mahendra provocó en las elecciones democráticas de 1957, acabando en prisión ${ }^{20}$.

17 A. APPADURAI, La modernidad desbordada. Dimensiones culturales de la globalización, Minnesota, 2001.

${ }^{18}$ M. LIETCHY, Fashioning modernity in Kathmandu...

${ }^{19}$ P. KHAREL, Media Practices in Nepal, Kathmandu, 2001.

${ }^{20}$ M. HUTT, Op.cit. 
“Excesivamente digno, héroe de Nepal: ¡Birendra Zindabad!

Pacificador, héroe de la tierra y el cielo: ¡Birendra Zindabad!

Tu gran antepasado logró la unificación de Nepal, Tu abuelo marcó el comienzo de la Democracia,

Tu honorable padre logró la Nepalización, Hoy en día fortaleces la Nación Real.

Firme, puro y sabio, ¡Birendra Zindabad! Excesivamente digno, héroe de Nepal: ¡Birendra Zindabad!" 21

A partir de los 60, poetas y escritores organizaron muchos movimientos de contenido socio-político, como el movimiento Aswikrit Jamat (Generación Literaria Rechazada) que comenzó con la publicación de historias cortas en el periódico Sanjivani en 1968, e implicaba a escritores como Shailendra Sakar, Kavitaram, Parashu Pradhan y Ramesh Sheshtra. A través de una literatura secular en su contenido e informal en su tono, expusieron una especie de socialismo realista. Del mismo modo, como respuesta a la Back to the Village National Campaign (Campaña Nacional del Retorno al Pueblo), llevada a cabo por el gobierno entre 1967 y 1975 con la intención de popularizar el sistema Panchayat, se originó la Revolución de Poesía en la Calle, ligada a una demostración de estudiantes que acabó con la declaración de un Referéndum Nacional. En esta revolución cientos de poetas recitaron sus obras en las calles de Katmandú, demandando abiertamente el fin del sistema Panchayat. Para Ashesh Malla, director del teatro Sarwanam "La Revolución de Poetas en la Calle tiene una relación cercana con el "Teatro de Calle", pues fue la idea que trajo al teatro fuera del ámbito cerrado"22. Asimismo, los escritores organizaron el movimiento Boot Polish (Limpia Botas) también como respuesta a la Back to the Village National Campaign y censura general. En esta manifestación, escritores y editores se reunieron en Katmandú

${ }^{21}$ Bhupi Sherchan. Parodia sobre el sistema Panchayat, en M. HUTT, Op.cit, p. 174.

${ }^{22}$ En S. UPRETI y R. PIYA, A Collection of Essays on Art and Theatre in Kathmandu, Kathmandu, 2011. y se dedicaron a limpiar los zapatos de los paseantes durante una semana en señal de protesta. Su intención era demostrar sus sentimientos como intelectuales nepalíes sin ninguna posibilidad de futuro ${ }^{23}$.

“...Nubes de polvo sobre la tierra y el aire;

Soplido, contados soplidos y huelgas y lucha,

$\mathrm{Y}$ estallando y rugiendo y las lluvias vertidas por dentro,

Aquí, allí y en todas partes los relámpagos lucen feroces

Pero, en la mañana siguiente, yo escucho.

Los grandes árboles se han roto,

La basura de las calles ha desaparecido

¡Y los cultivos están floreciendo!

Entonces me siento con ganas de ver,

¡Una revolución barriendo mi tierra!"24

El teatro llegó a Nepal a principios del siglo XX. Era un teatro de élite, en el que las mujeres nunca participaban, salvo como audiencia. Pero a partir de los 60, las mujeres comenzaron a ejercer como actrices y a ser representadas de forma reivindicativa, como en la famosa pieza teatral Masan (El patio, 1945 $)^{25}$ en la cual se muestra claramente cómo la mujer se subleva ante la sociedad Patriarcal. El primer teatro de calle no ocurrió hasta 1982 en las premisas de la Tribhuvan University con la performance Murdabad ma Utheka Hathharu (Manos alzadas en protesta) escrita por Ashesh Malla con el grupo

${ }^{23} \mathrm{M}$. HUTT, Nepal in the Nineties.Versions of the past, visions of the future, Oxford,1994.

${ }^{24}$ Kedar Man Vyathit, Andhi (La Tormenta), 1956; en M. HUTT, Himalayan Voices. An Introduction to Modern Nepali Literature, Oxford, 1991, p. 70.

${ }^{25}$ Masan (El Patio, 1945) de Gopal Presad Rimal no solo desafió las normas impuestas sino que inició todo un nuevo movimiento de mujeres actrices. Masan es la historia de una esposa que no puede concebir. Frustra$\mathrm{da}$, pide a su marido que se case de nuevo y tenga un hijo aunque no sea suyo biológicamente. La segunda mujer concibe un bebé, mientras que la primera descubre que no podía quedarse embarazada debido a unas píldoras que su marido la administraba en secreto. El acto concluye con la primera mujer abandonando a su marido, algo insólito en Nepal. En S. UPRETI y R. PIYA, Op.cit. 
de teatro Sarwanam ${ }^{26}$. Esta obra reclamaba abiertamente el fin del sistema Panchayat. Así fue como poco a poco comenzaron a crearse nuevas academias de teatro social, como Aarohan $^{27}$. Los críticos más conservadores opinan que los grupos teatrales son un tipo de ONG, y que en su intento por conseguir financiación muchos grupos de teatro han reducido el teatro de calle a un mero teatro de propaganda. Por otro lado Abhi Subedi subraya que al optar por el teatro de calle estos nuevos grupos se dirigen a una nueva audiencia, diseminando el mensaje que aporta a las clases más bajas de la jerarquía social nepalí y provocando eficazmente la lucha por el cambio ${ }^{28}$.

También la caricatura nepalí fue utilizada como medio de expresión subversiva en contra del régimen. Las primeras caricaturas en Nepal tienen su origen en el festival Gai Jatra, durante el cual se permite la crítica política o social sin represión alguna. La caricatura moderna floreció oficialmente a partir de 1960, cuando este tipo de dibujo político comenzó a aparecer de manera constante en los periódicos públicos como protesta humorística ${ }^{29}$. En 1976 la Royal Nepal Academy (RNA) organizó durante el festival Gai Jatra

${ }^{26}$ El grupo de teatro Sarwanam comenzó su actividad en 1982 siendo hoy en día uno de los grupos de teatro líderes en Nepal. Al introducir formas de teatro alternativas, que requieren pocos elementos en el escenario, este grupo ha superado las barreras del teatro para las élites, alcanzando a todas las esferas de la sociedad. Es el grupo pionero en la organización del Teatro de Calle. (en línea), consultado el 10 de Febrero de 2015. URL: http://sarwanam.org.np/

${ }^{27}$ Este grupo trabaja para crear un movimiento de teatro con obras tradicionales de su país, así como obras occidentales adaptadas al contexto nepalí. Asimismo, fomentan el teatro ayudando a las comunidades de Nepal a establecer sus propios grupos teatrales y así puedan utilizar esto como un arma para mejorar la calidad de sus vidas. Aarohan Theatre Group (en línea), consultado el 10 de Febrero de 2015. URL: http://kathmandu. im/aarohan-theatre-group/

$$
{ }^{28} \text { S. UPRETI y R. PIYA, Op.cit. }
$$

${ }^{29}$ Durante los 60 y 70 la mayoría de los dibujos se realizaban sobre madera por lo que la calidad no era muy buena, por lo tanto su desarrollo estuvo directa-

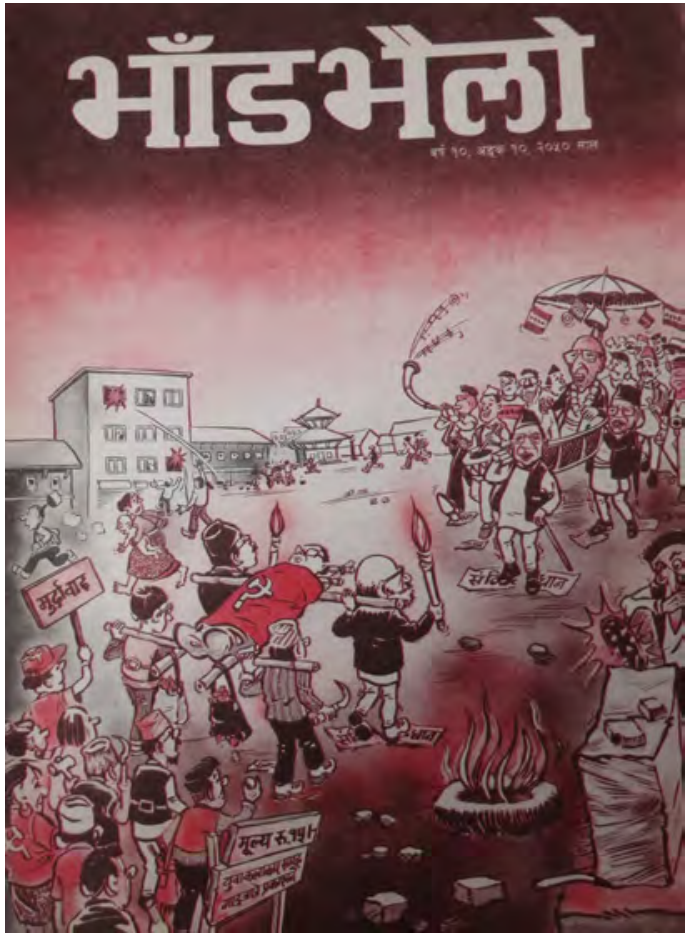

- Fig. 3. Revista humorística publicada durante el festival Gai Jatra por el colectivo SKIB-71 en colaboración con el Young Artist Group [ca. 1980]. Cortesía de Krishn Manandhar.

una exhibición de caricaturas y en 1990 la Humor and Satire Sociey (Sociedad de Humor Satírico) organizó durante este mismo festival una competición de dibujo (Fig. 3).

Fue entonces cuando comenzaron a surgir los caricaturistas más importantes, como Diresh Dahal o Durga Baral ${ }^{30}$. Asimismo, el dibujo animado se desarrolló a la par que la introducción de la televisión, en $1985^{31}$. En 1987 las ONGs Unicef y Worldview International Fundation organizaron un taller de dos

mente relacionado con el desarrollo de la imprenta en Nepal.

${ }^{30}$ R. K. PANDAY, Nepalese cartoons. A portfolio of cartoons of Nepal by representative cartoonists, Kathmandu, 1997.

${ }^{31}$ El hecho de que los programas extranjeros fuesen más baratos que la producción local fomentó que la programación incluyese cada vez más productos extranjeros hasta que en 1990, con la llegada de la Democracia, la televisión emitía programas europeos, americanos, indios y nepalíes. En P. ONTA, Mass media in post-1990 Nepal, Kathmandu, 2006. 
semanas titulado "Animación para la supervivencia de los niños". En dicho taller dos animadores checos, Peter Fasinok y Thomas Horovic, mostraron a 16 artistas nepalíes las técnicas del dibujo animado. En 1989 se produjo la primera película animada nepalí, la cual fue financiada por la ONG Solid Waste Management, y también en 1994 se creó el Art $\mathcal{E}$ Cartoon Studio, como el primer estudio de dibujo en Nepal con la ayuda financiera de Japón. En consecuencia, la animación nepalí siempre ha tratado sobre temas educativos y medioambientales al estar las ONGs involucradas en el proceso de los mismos ${ }^{32}$.

Por otra parte, el primer cine de $\mathrm{Ne}$ pal fue construido en 1943 por Jung Bahadur Rana solo para la élite de palacio, y no fue hasta 1949 que el cine público Janaseva abrió en Katmandú. En sus comienzos los monarcas mantuvieron un estricto control sobre lo que se proyectaba, favoreciendo las películas hindúes más conservadoras, siendo Rambibaha (La boda de Ram) la primera película que se estrenó en sus salas ${ }^{33}$. El cine representó el inicio de una nueva cultura de consumismo visual y el comienzo de nuevos estilos y deseo de libertad. Por ejemplo, en la película Jeevan Yatra de 1946 vemos cómo la moda es clave en el rol romántico de la película. Rodada en la zona rural, la mujer viste con un sari tradicional de principio a fin, excepto en los interludios románticos. En una de las escenas de la película el héroe cae dormido y sueña con el romance con su heroína, ambos llevan ropas modernas al estilo occidental. Sin embargo, la industria del cine nepalí no tuvo demasiado éxito, produciendo solo unas pocas películas y dando paso al cine indio como el favorito de los nepalíes ${ }^{34}$. Asimismo, el cine también influenció en el ámbito de la música nepalí ya que las

${ }^{32}$ R. K. PANDAY, Op.cit.

${ }^{33}$ En esos días los cines de Katmandú dividían sus localidades en clases bajas y altas. Mientras que las clases bajas sentadas en la parte inferior silbaban y aplaudía, las clases altas mantenían su decoro en la parte superior.

${ }^{34}$ M. HUTT, Nepal in the Nineties... melodías modernas de la industria cinematográfica llegaban a toda la población por vía de Radio Nepal. Así comenzaron a observarse cambios en la música tradicional, como en el caso de Ambar Gurung quien transformó once poemas de Bhupi Sherchan en música siguiendo este nuevo estilo moderno ${ }^{35}$. También la música Panche Bāja ${ }^{36}$, antes dedicada a motivos religiosos y místicos, adoptó los instrumentos occidentales ${ }^{37}$. Asimismo, a partir de los 60 se desarrolló la música rock nepalí. La banda Rapha se estableció en 1967 como un grupo de guitarristas influenciado por Los Beatles o Bob Dylan, y tocaban canciones sobre la resistencia y oposición al sistema Panchayat por los pueblos de $\mathrm{Nepal}^{38}$. En 1971 algunos miembros del grupo partieron al este parando en los pueblos para cantar sus canciones, evadiendo la censura ${ }^{39}$. El grupo se disolvió cuando la mayoría se unió al Communist Party unos años después.

\section{LA PINTURA MODERNA}

La pintura nepalí también sufrió un proceso de transición, aunque dicho proceso aún no está del todo definido por los historiadores del arte. Mientras que el crítico de arte Madan Chitrakar alega que los pintores

${ }^{35} \mathrm{M}$. HUTT, The life of Bhumpi Sherchan...

${ }^{36}$ La música Panche Bāja fue introducida por los musulmanes posiblemente en el siglo XIV, con una mezcla de instrumentos de viento, tambores y cimbales. Esta música solo puede ser tocada por una casta de músicos profesionales denominados los Damai, considerada como una de las más bajas de la escala jerárquica nepalí. Las antiguas experiencias de los músicos del Nepal central relatan que antes, durante las bodas, una secuencia de música era tocada como bendición para la pareja de recién casados. Actualmente, los músicos no son capaces de tocar estas piezas. En C. TINGEY, Auspicious Music in a Changing Society. The Damai Musicians of Nepal, vol. 2, London, 1994.

${ }^{37}$ Uno de los ítems más populares en los repertorios Panche Bāja fue la banda sonora de la película nepalí $\mathrm{Ku}$ sume Rumal de 1986. Ibídem.

${ }^{38}$ M. HUTT, The life of Bhumpi Sherchan...

${ }^{39}$ Este viaje es recordado en las memorias de Manjul, Pasos de la Memoria. En M. HUTT, The life of Bhumpi Sherchan..., p. 87. 
realistas fueron los primeros modernos en el arte nepalí, Mukesh Malla advierte que estos artistas no pueden ser denominados como "modernos" pues sus obras se producían dentro del marco del realismo. Según Malla, la modernidad comenzó en el año 1962 tras la exhibición de pinturas abstractas de Lain Singh Bangdel, el cual es considerado como el "padre de la modernidad" en $\mathrm{Nepal}^{40}$, a pesar de que existen otros artistas como Urmila Upadhyaya Garg ${ }^{41}$ o Uttam Nepalí ${ }^{42}$, que también exhibieron sus obras modernas en la misma época. Asimismo el artista Gehendra Man Amatya reclama reconocimiento por su exhibición de pintura abstracta en 1954, mucho antes de la primera exhibición de Bangdel en Katmandú ${ }^{43}$. (Fig. 4)

Ante los hechos, Mukesh Malla subraya que la exposición de Bangdel es la más relevante en cuanto al desarrollo del arte moderno nepalí, puesto que fue la que causó mayor impacto $^{44}$. Podríamos decir que la carrera artística de Lain Singh Bangdel como pintor comenzó en torno a 1950 cuando, con la ayuda económica del General Keshar Shumsheree Rana, se mudó a París en plena época de Vanguardia, siendo influenciado por la pintura de Pablo Picasso y Georges Braque. Por aquella época Bangdel se encontró con el famoso colectivo indio Progressive Artists Group, que se encontraba en París, y en 1955 expuso junto a ellos en la exhibición Indian Paintres au Paris (Pintores Indios en París). Un año más tarde,

40 M. CHITRAKAR, Nepali Art. Issues Miscellany, Kathmandu, 2006.

${ }^{41}$ Siendo reconocida como la primera mujer artista nepalí de la historia, Upadhyaya acabó fundando una escuela de arte textil llamada Nepal Srijanatmak Kala Guthi para ayudar a su país, así como la fundación Society of Friends of Nepal (SOFON).

${ }^{42}$ Uttam Nepalí pasó su infancia en Lucknow. Comenzó a interesarse por el arte abstracto al comprobar el placer espiritual que le producían debido a sus diversas formas de expresión.

${ }^{43}$ G. M. AMATYA, Modern Art, Kathmandu, 2005.

44 U. SHARMA, "Emergence of Nepali modern art", en Spaces Nepal, 2013 (en línea), consultado el 8 de Febrero 2015. URL: http://spacesnepal.com/archives/ jun13/2013F13.php

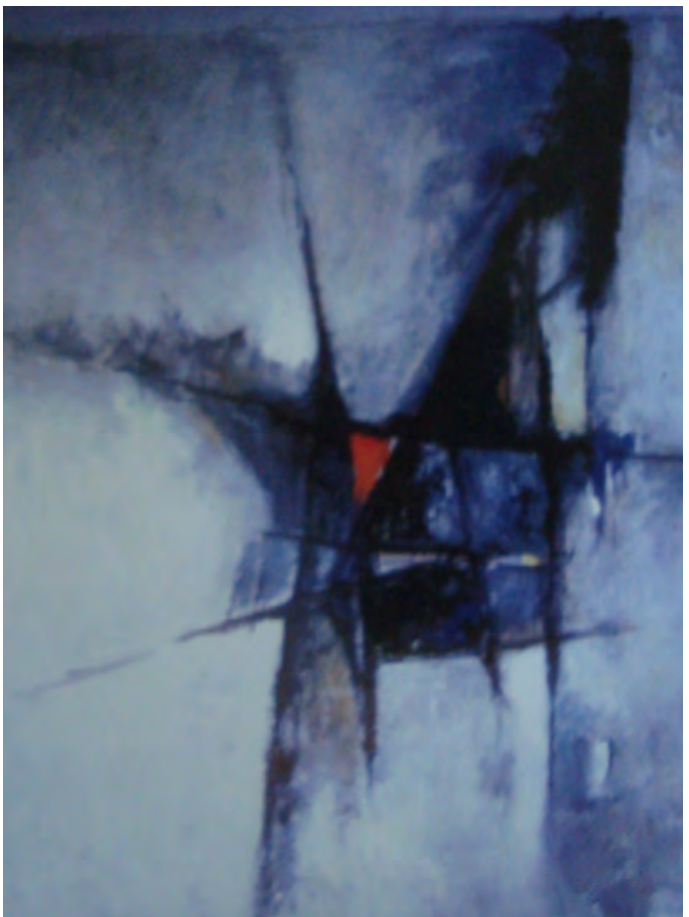

- Fig. 4. Lain Singh Bangdel. Sin título. 1960. Colección de Dina Bangel.

Bangdel se mudó a Londres, donde se dejó llevar por el expresionismo abstracto. Según sus palabras: “Cuando aún estaba en París comencé a trabajar en el nuevo estilo abstracto... el estilo de los artistas alrededor del mundo. Me forcé a mi mismo porque ese era el estilo, quería evolucionar y destacar. Limitándome a hacer figuras nepalíes, escenas nepalíes en París ¿Quién las reconocería? ¿Quién las compraría? Por eso decidí unirme al movimiento internacional" ${ }^{\prime 45}$.

En 1957 B.P. Koirala viajó a Londres y encomendó a Bangdel comprar algunas reproducciones a fin de organizar una exhibición de arte moderno en Nepal. Tres años más tarde Koirala volvió a Londres para solicitar a Bangdel su regreso a Katmandú y organizar la apertura de una galería de arte moderno con dichas reproducciones. Tras la destitución del Ministro ese mismo año sería el mismo Rey Mahendra quien se encargó del retorno de Bangdel. Según Abhi Subedi, el arte abstracto interesaba a Su Majestad pues reflejaba el estado moderno

${ }^{45}$ D. BANGDEL y D. MEESSERSCHMIDT, Op.cit. 


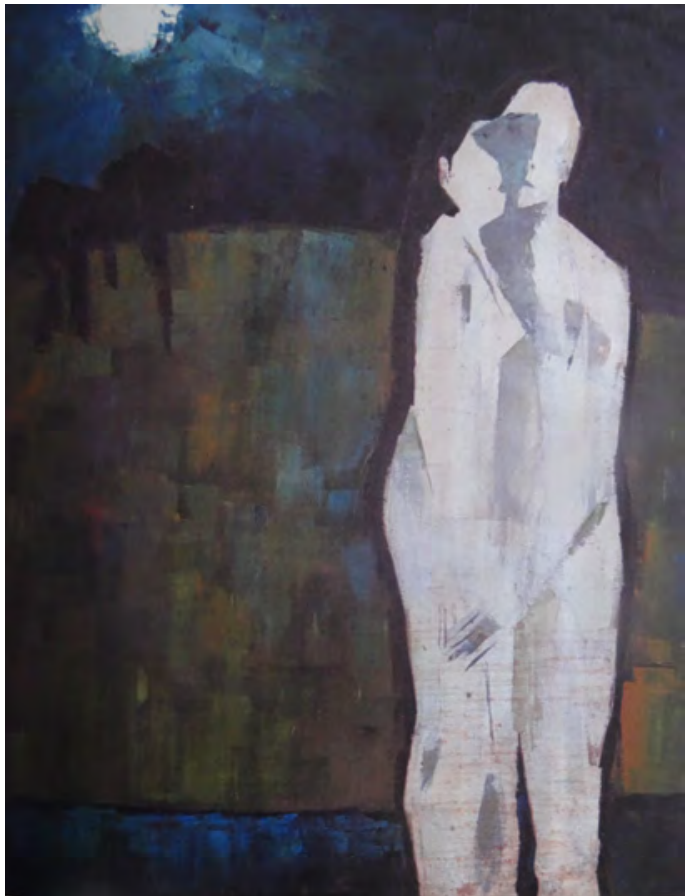

- Fig. 5. Rama Nanda Joshi. Couple (Pareja). 1963. Rama Nanda Joshi Museum en Park Gallery, Katmandú.

que el monarca pretendía crear como reflejo internacional de $\mathrm{Nepal}^{46}$. Así pues, Lain Singh Bangdel volvió a Nepal en 1961, y en 1962 se organizó su primera retrospectiva ${ }^{47}$ $\mathrm{y}$, a partir de entonces, surgió una nueva generación de artistas que comenzó a experimentar buscando su propio camino a través de la individualidad y la originalidad en sus obras modernas ${ }^{48}$. Otro de los artistas más relevantes entre los que por esa época volvieron a Nepal fue Rama Nanda Joshi, quien graduado en la Sir J.J. School of Art de Calcuta, reflejaba en su pintura el nuevo pensamiento liberador característico del momento (Fig. 5).

${ }^{46}$ A. SUBEDI, "Nepali art: Nepali utopia”, Nepalese Studies, n²2, 1995, pp.113-130.

${ }^{47}$ A pesar de que Bangdel siempre intentó mantenerse al margen de los temas políticos, su relación con Koirala era particularmente sólida. Cuando volvió a Nepal decidió hacerle un retrato como tributo, sacándolo a la luz en el mismo año en que se abolía el régimen Panchayat, tras el Jana Andolan de 1990. D. BANGDEL y D. MEESSERSCHMIDT, Op.cit.

\footnotetext{
${ }^{48}$ A. SUBEDI, Op.cit.
}

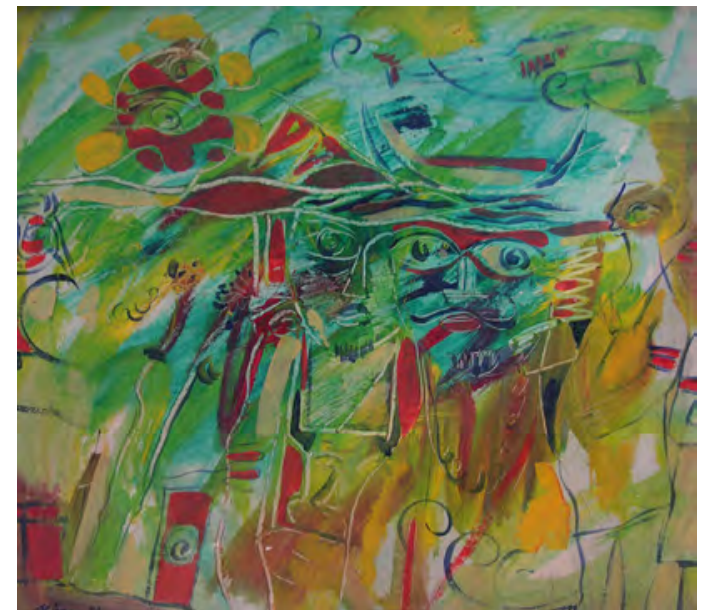

- Fig. 6. Kiran Manandhar. Gai Jatra. 1987. Colección de Sagar Manandhar.

De esta manera comenzó la moda de las exhibiciones de grupo en la ciudad, aunque sin ningún tipo de mensaje colectivo. Los artistas Shashi Bikram Shah, Krishna Manandhar, Indra Pradhan y Batsa Gopal Vaidya, también graduados en Sir J. J. School of Art, se unieron para formar el colectivo SKIB-71. Dentro de este colectivo había una gran diversidad de temas y estilos, desde la representación mitológica de Shashi Shah hasta los motivos religiosos de Batsa Gopal, pasando por las máscaras rituales de Indra Pradhan o las extensivas exploraciones del arte abstracto de Krishna Manandhar ${ }^{49}$. Por otro lado, los 80 representaron un nuevo período con una llegada de una nueva generación de pintores graduados en el extranjero. Algunos artistas, como Birendra Pratap Singh, comenzaron a experimentar con dibujos surrealistas e imágenes distorsionadas del Katmandú histórico, y otros, como Mukesh Malla y Kiran Manandhar, buscaron la espontaneidad de la abstracción en su obra (Fig. 6).

Al mismo tiempo que el movimiento de arte moderno comenzaba a proliferar, se abrieron nuevos centros y academias de arte con la intención de fomentar su desarrollo. La Royal Nepal Academy (RNA) ${ }^{50}$ fue

\section{${ }^{49}$ M. CHITRAKAR, Op.cit.}

${ }^{50}$ Nepal Academy (En línea), consultado el 30 de Febrero de 2015. http://www.nepalacademy.org.np 


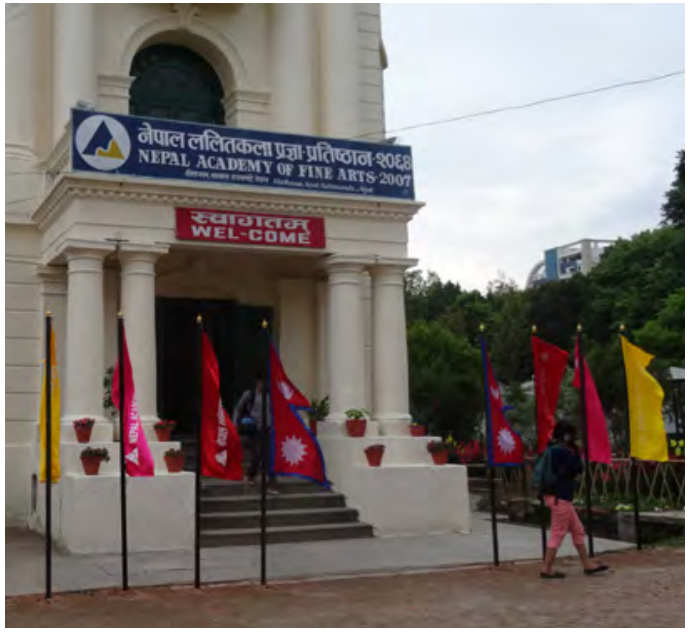

- Fig. 7. National Academy of Fine Arts, 2015. Foto de la autora.

fundada por el Rey Mahendra en 1957 para la promoción y preservación de la literatura y las artes. El mismo Rey era el Canciller y nombró a Lain Singh Bangdel Vicecanciller de la institución. El Príncipe Birendra, hijo de Mahendra, declaró "La RNA pretende eliminar todos aquellos obstáculos que dificulten la apreciación de la gloriosa herencia cultural de la región del Himalaya, que ha crecido con el paso del tiempo y se ha nutrido de la tradición original del país"51. Los poetas del grupo Rodi fueron invitados a formar parte de la academia, pero debido a la conexión entre el gobierno Panchayat y la Royal Nepal Academy no quisieron colaborar. La academia ofreció al grupo Rodi la publicación de un libro recopilando sus poemas, a lo cual se accedió no sin antes acordar que los miembros de la academia no leerían los poemas antes de publicarlos. Al ser quebrantado el acuerdo, los poetas acabaron rompiendo las obras, significando este suceso el fin del colectivo.

En 1968, el Rey Birendra delegó el puesto de Canciller al poeta Kedar Man Byathit, que había sido un exiliado en los años 40 en la India y había estado en prisión por sus movimientos anti-Rana. Byathit declaró: "Espero que la academia represente un lugar idóneo para las aspiraciones intelectuales del país, unificando la nación a través de

\footnotetext{
${ }^{51}$ Modern Nepali Poems, Kathmandu, 1972, p. 3.
}

la belleza revelada en la acción y el carácter propiamente nepalí". Finalmente tras el Jana Andolan (Movimiento del Pueblo) de 1990, la Royal Nepal Academy acabó separándose de Palacio, pasándose a llamar simplemente Nepal Academy ${ }^{52}$.

Por otro lado, el Príncipe Birendra, con el apoyo del Rey, fundó la Nepal Association of Fine Arts (NAFA) en 1965, siendo el primer establecimiento artístico construido con la intención de representar el arte del Estado a nivel internacional, lo cual significó un empuje moral para el desarrollo del arte en Nepal. Lain Singh Bangdel, que también estaba a cargo de la NAFA, envió un prospecto de arte nepalí a galerías y museos de todo el mundo para mostrar el núcleo de arte moderno que emergía en el país. La idea inicial era la de formar un museo, pero como no tenían obras suficientes se conformaron con montar una galería: la Birendra Art Gallery, para la cual la Casa Real hizo una selección de las obras de arte más representativas de la modernidad en $\mathrm{Nepal}^{53}$ (Fig. 7).

Tanto la NAFA como la RNA ofrecían prestigiosos puestos de trabajo, para los cuales conseguir el favor de palacio era relevante. Al mismo tiempo, existía un cierto núcleo corrupto en el que los miembros de la academia compraban obras de sus compañeros con el dinero de la NAFA, o las suyas propias $^{54}$. Así pues, como alternativa a

${ }^{52}$ D. BANGDEL y D. MEESSERSCHMIDT, Op.cit.

${ }^{53}$ La NAFA dividió las artes de Nepal en tradicionales y contemporáneas, pero esta división originó un problema ya que ambas tendencias tienden a mezclarse por naturaleza.

54 Por ejemplo, según el crítico Madan Chitrakar, cuando Uttam Nepalí presidía el consejo de la NAFA se las arregló para recopilar en torno a diecisiete de sus propias obras en este lugar prestigioso y quedarse él con los beneficios. Del mismo modo cada uno de sus compañeros en la NAFA seleccionaron entre diez y quince de sus propias obras nombrándolas como piezas históricas, mientras que muchas otras obras permanecieron ignoradas. En M. CHITRAKAR “Nepali Art Has Ugly Faces Too", Arts of Nepal, 2011 (en línea), consultado el 5 de Febrero de 2015. URL: http://www.artsofnepal.com/ nepali-art-news/31/nepali-art-has-ugly-faces-too.html 


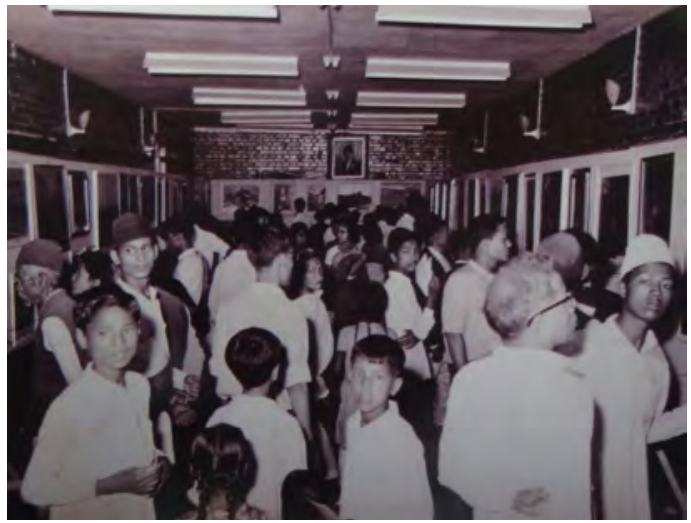

- Fig. 8. Exhibición de reproducciones de pintura europea. 1969. Art Council. Foto de Art Council.

la institución pública dominada por el Rey, comenzaron a surgir galerías de arte privadas. El Nepal Arts Council es una institución a caballo entre lo público y lo privado. Se creó en 1963 con la idea de promocionar el arte moderno internacional en Nepal a través de la muestra de las reproducciones traídas por Lain Singh Bangdel desde Europa. Lain Singh Bangdel fue nombrado secretario, y gracias a una generosa donación del General Keshar Shumsheree Rana pudo coleccionar obras de arte moderno, continuando así el proyecto que había comenzado durante su estancia en París (Fig. 8).

Como galerías completamente independientes, destacan Park Gallery ${ }^{55}$, fundada por Rama Nanda Joshi en 1970 como la primera galería de arte moderno independiente de Nepal, donde además se impartían clases de arte, o la Siddhartha Art Gallery ${ }^{56}$ abierta en 1987 como un espacio de arte contemporáneo internacional dirigido por la comisaria Sangeeta Thapa, y punto de encuentro para las nuevas generaciones de Nepal.

${ }^{55}$ La Park Gallery se encuentra en Patán, siendo un lugar histórico al ser la primera galería de arte moderno de Nepal. Hoy en día esta galería es dirigida por los familiares de Rama Nanda Joshi, y en ella pueden verse las obras de este artista. Park Gallery (en línea), consultado el 24 de Marzo de 2015. URL: http://www. parkgallery.com.np/

56 Siddhartha Art Gallery (en línea), consultado el 15 de Febrero de 2015. URL: http://www.siddharthaartgallery.com/
En 1990 se desató el Jana Andolan que acabaría por fin con el sistema Panchayat ${ }^{57}$. Tras la revolución se comenzó a respirar un ambiente de mayor libertad de expresión. Los individuos pertenecientes a las instituciones académicas y culturales se vieron a sí mismos en una posición precaria. Por ejemplo, casi todos los miembros de la NAFA resignaron de su puesto al darse cuenta de que el régimen que les había elegido estaba totalmente desacreditado ${ }^{58}$. Los discípulos de Lain Singh Bangdel, quien por entonces impartía lecciones de arte moderno en la NAFA, formaron el colectivo New Art Circle y en 1990 organizaron una exhibición en el Nepal Arts Council, a pesar de que la existencia de éste ya comenzaba a ser cuestionada por los revolucionarios así como los favoritismos de la Casa Real hacia el mismo Bangdel ${ }^{59}$. A pesar de las críticas, el artista continuó con sus proyectos y en 1990 realizó la serie Fighting for Democracy (Lucha por la democracia), con una aplicación del color amplia y libre, y un intenso efecto dramático.

En los años venideros se abrieron otros centros como el Kathmandu Contemporary Arts Center (KCAC) en $2007^{60}$ o LASANAA en 2011, como espacios alternativos para la creación ${ }^{61}$. Asimismo, la apertura de la

${ }^{57}$ La prensa fue dominada desde los primeros días del movimiento, y los periódicos publicaban largos artículos en defensa de la Familia Real y el sistema Panchayat, omitiendo la información revolucionaria. Pero para entonces la poesía ya había cobrado mucha importancia como arma en el proceso del cambio político.

${ }^{58}$ La NAFA acabó siendo reconstituida por nuevos miembros elegidos por el nuevo Primer Ministro Krishna Presad Bhutari. Por desgracia, poco fue el cambio en el sistema de la academia, pues casi todos los nuevos miembros eran adeptos del Nepalí Congress, sin haber a penas representaciones del resto de partidos políticos. M. CHITRAKAR “Nepali Art Has Ugly Faces Too”...

59 O. SATTAUR, Nepal, New Horizons, Oxford, 1996.

${ }^{60}$ Kathmandu Contemporary Arts Centre (en línea), consultado el 2 de Abril de 2015. URL:http://www.kathmanduarts.org/Kathmandu_Arts/home.html

${ }^{61}$ Lasanaa (en línea), consultado el 2 de Abril de 2015. URL: https://lasanaa.wordpress.com/ 
escuela de arte Kathmandu University of Art and Design (KUART) en 2003 empujó la creación nepalí hacia ámbitos más experimentales ${ }^{62}$

\section{CONCLUSIÓN}

Desde la aparición de los británicos en India el arte nepalí comenzó a notar los influjos extranjeros a causa del afán de la monarquía Rana por todo lo relacionado con occidente. A su vez, el arte político emergía entre los poetas y escritores exiliados, creando un movimiento anti-Rana que pretendía acabar con el régimen e instaurar la democracia en el país. En 1950 los Rana fueron sustituidos por los Shah, los cuales pretendían reforzar la tradición nepalí a través del sistema Panchayat. Sin embargo el movimiento del arte moderno en Nepal ya había comenzado, reforzado por la llegada del turismo, la ayuda internacional y los nuevos medios. Hoy día las formas culturales de todas partes del mundo se encuentran en un inevitable proceso de fractura y yuxtaposición. ¿Cómo afrontar la división del pueblo nepalí entre la tradición de su herencia cultural y su inminente proceso de modernización? Arjun Appadurai indica, acertadamente, que la única manera de lograr entender la cultura global es dejar de comparar las culturas y aceptar el discurso politético ${ }^{63}$.

A lo largo de este ensayo hemos visto cómo el proceso de modernización cultural en Nepal ha sido originado desde la hibrida- ción de su propia cultura y las culturas extranjeras como parte de un proceso de evolución histórico, inevitable en los tiempos que corren. Considero que mirar la producción de los artistas modernos de la periferia como un arte "occidentalizado" es mirarlo a través de la cómoda lupa de occidente, pasando por alto el hecho que la cultura nepalí se caracteriza por haber sabido adoptar y adaptar todas las nuevas ideas e influencias a la suya propia sin ningún tipo de rechazo sino, más bien, de aprendizaje. Decir "colonizado" es una manera, a mi parecer, de marcar esa frontera entre ambos mundos, como forma de no-reconocimiento de los méritos de aquellos a los que no nos interesa reconocer y forma de subrayado de ciertos conceptos peliagudos como "Primer y Tercer Mundo". ¡Todo lo que nos perdemos con esta postura euro-centrista!

A través de este estudio se ha puesto de manifiesto que el arte actual del país ha de ser visto como consecuencia cultural de su introducción al mundo global y aceptando la modernidad nepalí como un proceso originado desde una realidad propia, que no occidental -aunque sin negar el hecho de que la mezcla con esta cultura haya sido uno de los detonantes del cambio-. En conclusión, salir de la "perspectiva global" para adentrarnos en las "perspectiva local" es una asignatura pendiente en Nepal, así como el del mundo en general, para comprender los esquemas que rigen la contemporaneidad a día de hoy.

${ }^{62}$ Kathmandu University School of Arts. Center for Art and Design (en línea), consultado el 30 de Abril de 2015. URL: http://kuart.edu.np/

${ }^{63}$ A. APPADURAI, Op.cit. 